\title{
Non-episodic Angioedema With Eosinophilia Successfully Treated With Reslizumab
}

\section{OPEN ACCESS}

Received: Sep 4, 2019

Revised: Oct 11, 2019

Accepted: Oct 31, 2019

Correspondence to

Ga-Young Ban, MD, PhD

Department of Pulmonary, Allergy and Critical Care Medicine, Kangdong Sacred Heart Hospital, Hallym University College of Medicine, 150 Seongan-ro, Gangdong-gu,

Seoul 05355, Korea.

Tel: +82-2-2152-1372

Fax: +82-2-477-6925

E-mail: rkduddle@hanmail.net

Copyright (C) 2020 The Korean Academy of Asthma, Allergy and Clinical Immunology .

The Korean Academy of Pediatric Allergy and Respiratory Disease

This is an Open Access article distributed under the terms of the Creative Commons Attribution Non-Commercial License (https:// creativecommons.org/licenses/by-nc/4.0/) which permits unrestricted non-commercial use, distribution, and reproduction in any medium, provided the original work is properly cited.

ORCID iDs

Hyunwook Chu (iD)

https://orcid.org/0000-0003-2336-0976 Dong-Ye Youn (iD)

https://orcid.org/0000-0001-6789-8706

Hae-Sim Park (D)

https://orcid.org/0000-0003-2614-0303 Young-Min Ye (D)

https://orcid.org/0000-0002-7517-1715

Yong Bum Park (D)

https://orcid.org/0000-0002-5814-6104 Ga-Young Ban (D)

https://orcid.org/0000-0002-7961-742X

Disclosure

There are no financial or other issues that might lead to conflict of interest.

\section{Hyunwook Chu $\mathbb{D}^{1}$, Dong-Ye Youn $\left(\mathbb{1},{ }^{1}\right.$ Hae-Sim Park $\mathbb{D}^{,},{ }^{2}$ Young-Min Ye $\mathbb{1},{ }^{2}$ Yong Bum Park $\mathbb{1},^{\prime}$ Ga-Young Ban $\mathbb{1}^{1,3^{*}}$}

\author{
'Department of Pulmonary, Allergy and Critical Care Medicine, Kangdong Sacred Heart Hospital, Hallym \\ University College of Medicine, Seoul, Korea \\ ${ }^{2}$ Department of Allergy and Clinical Immunology, Ajou University School of Medicine, Suwon, Korea \\ ${ }^{3}$ Allergy and Clinical Immunology Research Center, Hallym University College of Medicine, Chuncheon, Korea
}

To the editor,

Angioedema with eosinophilia $(\mathrm{AE})$ is a rare allergic disease characterized by recurrent episodes of angioedema, fever, weight gain, hypereosinophilia without internal organ damage. ${ }^{1} \mathrm{AE}$ has been classified into 2 variants, episodic angioedema with eosinophilia (EAE) and non-episodic angioedema with eosinophilia (NEAE). ${ }^{2}$ Most cases of AE in Korean and Japanese patients were recognized as non-episodic., ${ }^{2,3}$

Systemic corticosteroid is widely administered to relieve angioedema symptoms while some AE patients show frequent recurrences and steroid dependency, so that novel treatments for $\mathrm{AE}$ have been reported including imatinib ${ }^{4}$ and mepolizumab. ${ }^{5}$ Herein, we report the first case of NEAE treated with reslizumab, a monoclonal antibody against interleukin (IL)-5.

A 41-year-old woman visited the outpatient clinic of pulmonary, allergy, and critical care medicine, Kangdong Sacred Heart Hospital with painful and itchy edema of her extremities. Her peripheral edema was observed in both upper and lower extremities without urticaria and was accompanied by a bodyweight increase of $4 \mathrm{~kg}$ for 2 months (Figure A). She denied any use of drugs and history of insect bite or trauma. The symptoms of allergic rhinitis and conjunctivitis were stationary.

At the first visit, peripheral eosinophil count was 1,140/uL. There was no evidence of parasite infestation in serologic and stool tests. No specific findings were noted in thyroid/liver/kidney function tests, and peripheral blood smear. Serum level of immunoglobulin (Ig) M was 77.1 $\mathrm{mg} / \mathrm{dL}$ which was within the normal limit. The level of anti-nuclear antibody, $\mathrm{C} 1$ esterase inhibitor, and $\mathrm{C} 1$ inactivator activity were within the normal limit. The serum concentrations of IL-5 and eosinophil-derived neurotoxin (EDN) were measured to assess the status of eosinophil activation using commercially available ELISA Kits (IL-5, Abcam, Cambridge, MA, USA; EDN, MBL, Nagoya, Japan). Serum levels of eosinophil cationic protein were quantified by ImmunoCAP (Thermo Fisher Scientific/Phadia, Uppsala, Sweden). Written informed consent was obtained from the patient, and the study was approved by the Institutional Review Board of Kangdong Sacred Heart Hospital (KANDONG 2018-03-010-004). 

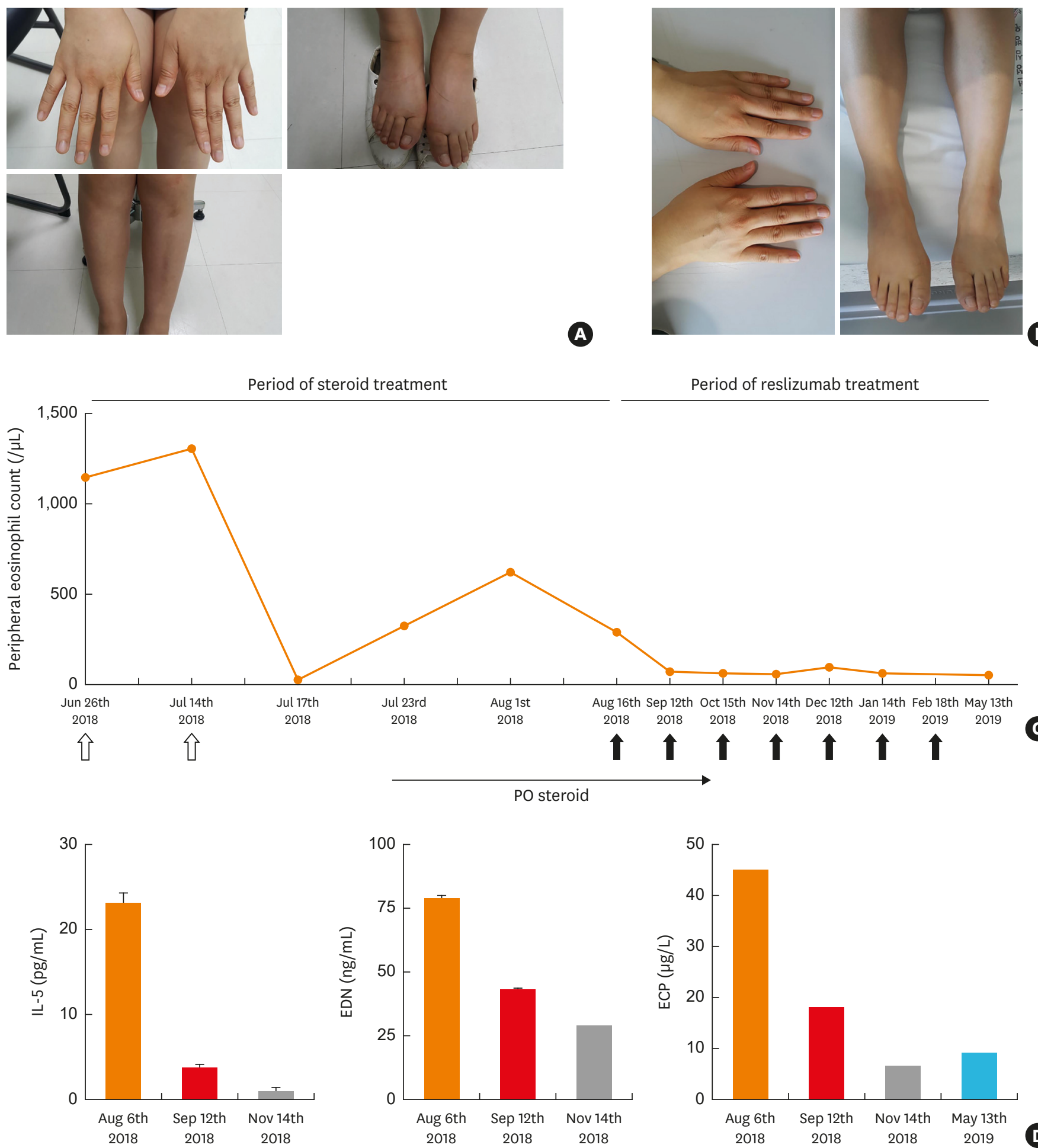

Figure. Change of angioedema and eosinophil inflammation markers before and after treatment with reslizumab. (A) Angioedema was observed on both upper and lower extremities accompanied by a body weight increase of $4 \mathrm{~kg}$. (B) Angioedema disappeared after treatment with reslizumab. (C) Elevated eosinophil count dramatically decreased after treatment with reslizumab. White arrows show the admission for intravenous corticosteroid injection and black arrows show reslizumab administration. (D)The levels of IL-5, EDN and ECP were decreased after treatment of reslizumab.

IL, interleukin; EDN, eosinophil-derived neurotoxin; ECP, eosinophil cationic protein. 
The patient was being treated with intravenous steroids (dexamethasone $15 \mathrm{mg} /$ day) for 4 days, and oral prednisolone was prescribed for 5 days ( $20 \mathrm{mg} /$ day). Ten days later, she visited the outpatient clinic for aggravated angioedema. Peripheral eosinophil count rose to $1,300 / \mathrm{LL}$. The second high-dose steroid therapy was performed, and oral prednisolone was maintained at a dose of $20 \mathrm{mg} / \mathrm{day}$. The prednisolone dose was tapered from 20 to $15 \mathrm{mg} /$ day for 1 month. However, her symptoms of angioedema relapsed and peripheral eosinophil count rose up to $620 / \mathrm{uL}$.

Due to persistent angioedema, eosinophilia which was refractory to antihistamine and showed failure to taper the steroid, we started reslizumab $170 \mathrm{mg}$ ( $3 \mathrm{mg} / \mathrm{kg}$ body weight) every 4 weeks. Persistent eosinophil activation status and angioedema despite the steroid therapy showed dramatic improvement (Figure B). Biologics are recommended to be continued if the clinical response is achieved in severe asthma. ${ }^{6}$ However, NEAE is known to be transient, we tried to stop reslizumab treatment as symptoms are relieved. After a reslizumab treatment period of 7 months and a follow-up period of 4 months, there were reductions in the daily maintenance dose of prednisolone ( $15 \mathrm{mg} v \mathrm{~s} .0 \mathrm{mg}$ ), the peripheral eosinophil count, and the serum levels of IL-5, EDN, and eosinophil cationic protein (Figure C and D).

Recently, there has been a growing number of studies using eosinophil-targeted biologics (anti-IL-5 antibodies) in eosinophilic disorders including hypereosinophilic syndrome, eosinophilic granulomatosis and polyangiitis, eosinophilic esophagitis, and other disorders. ${ }^{7}$ We report here a case of NEAE successfully and safely treated with reslizumab.

In conclusion, this is the first report to treat NEAE with reslizumab. Reslizumab is a treatment option in patients with NEAE.

\section{ACKNOWLEDGMENTS}

This work was supported by the National Research Foundation of Korea (NRF) grant funded by the Korea government (MSIP) (No. 2017R1A2B4010060) and a grant No. 20181817181800110 from the Kangdong Sacred Heart Hospital Fund.

\section{REFERENCES}

1. Gleich GJ, Schroeter AL, Marcoux JP, Sachs MI, O'Connell EJ, Kohler PF. Episodic angioedema associated with eosinophilia. N Engl J Med 1984;310:1621-6. PUBMED | CROSSREF

2. Cho HJ, Yoo HS, Kim MA, Shin YS, Ye YM, Nahm DH, et al. Clinical characteristics of angioedema with eosinophilia. Allergy Asthma Immunol Res 2014;6:362-5. PUBMED | CROSSREF

3. Nakachi S, Inokuma S. Eleven cases of angioedema with eosinophilia treated in a single hospital in Japan. Allergol Int 2012;61:259-63. PUBMED | CROSSREF

4. Scranton SE, Wild CA, England RW. Episodic angioedema with eosinophilia: successful treatment with imatinib. Ann Allergy Asthma Immunol 2008;100:172-4. PUBMED | CROSSREF

5. Matucci A, Liotta F, Vivarelli E, Dies L, Annunziato F, Piccinni MP, et al. efficacy and safety of mepolizumab (anti-Interleukin-5) treatment in Gleich's syndrome. Front Immunol 2018;9:1198. PUBMED | CROSSREF 
6. McGregor MC, Krings JG, Nair P, Castro M. Role of biologics in asthma. Am J Respir Crit Care Med 2019;199:433-45.

PUBMED | CROSSREF

7. Legrand F, Klion $\mathrm{AD}$. Biologic therapies targeting eosinophils: current status and future prospects. J Allergy Clin Immunol Pract 2015;3:167-74.

PUBMED | CROSSREF 